\section{Isolation of a Novel Sex Hormone, Tremerogen A-10, Controlling Conjugation Tube Formation in Tremella mesenterica Fries}

Youji SaKagami, Akira IsogaI, Akinori SUZUKI, Saburo TAMURA, Eiko TsuchiYA* and Sakuzo FukUi*

Department of Agricultural Chemistry and

*Institute of Applied Microbiology, The University of Tokyo, Bunkyo-ku, Tokyo 113

Received March 15, 1978

Tremella mesenterica Fr., a Basidiomysete, is dimorphic, producing a homokaryotic yeast-like form as well as a typical dikaryotic mycelium and the basidiospores on dikaryotic mycelium germinate to form homokaryotic cells, which ordinarily propagate by budding. " Between two compatible homokaryotic cells, the mating of both cells readily occures leading to a dikaryotic mycelium. In the mating process of $T$. mesenterica, formation of conjugation tube is controlled by a single pair of alles, $A$ and $a$ types, but production of a typical dikaryon is regulated by a series of " $B$ factors".;)

In 1965, Bandoni found that the $A$ and $a$ mating type cells each produce the diffusing hormone(s) (erogen) effective in inducing the conjugation tube in the opposite type cell. ${ }^{3 \text {. }}$ Recently Reid partially purified the hormon(s), which were suggested to be heterogeneous. ${ }^{4}$ )

With a view to clarifing the mating process of T. mesenterica from a chemical stand point, we attempted to isolate the hormon produced by $A$ type cell (IFO 559-1 9310) which induces the formation of conjugation tube in $a$ type cell (IFO 559-8 9313). In this paper, we wish to report the isolation and some chemical properties of the hormone termed tremerogen A10.

$A$ type cells were cultured in a fermentation tank (200 liters) with aeration and agitation at $25^{\circ} \mathrm{C}$ for $42 \mathrm{hr}$, culture medium; $2.5 \%$ glucose, $0.5 \%$ peptone, $0.4 \%$ yeast extract, $0.1 \%$
Culture filtrate (160 liters)

Adsorption on Amberlite XAD-7

eluted with $40 \%$ EtOH containing $5 \%$ $\mathrm{MgSO}_{4} \cdot 7 \mathrm{H}_{2} \mathrm{O}$

Extraction with $n$-BuOH: EtOH $(10: 3)$

Chromatography on Fractogel PGM-2000

with $60 \% \mathrm{MeOH}$

Adsorption on Amberlite XAD-2

eluted with $80 \%$ EtOH

Ion exchange chromatography on SP Sephadex C-25 with pyridine acetate buffer

Chromatography on Merckogel OR-6000

with $\mathrm{MeOH}: \mathrm{CHCl}_{3}: \mathrm{AcOH}(47: 47: 6)$

Chromatography on Fractogel PGM-2000

$\downarrow$ with $80 \% \mathrm{MeOH}$

Chromatography on Fractogel PGM-2000

with $80 \% \mathrm{MeOH}: \mathrm{AcOH}(99: 1)$

Chromatography on Fractogel PGM-2000

I with $80 \% \mathrm{MeOH}: \mathrm{AcOH}(94: 6)$

Chromatography on Fractogel PGM-2000

\with $\mathrm{MeOH}: \mathrm{H}_{2} \mathrm{O}: \mathrm{AcOH}(85: 5: 10)$

Tremerogen A-10 (1.6 mg)

FIG. 1. Isolation Procedure of Tremerogen A-10.

$\mathrm{KH}_{2} \mathrm{PO}_{4}, 0.05 \% \mathrm{MgSO}_{4} \cdot 7 \mathrm{H}_{2} \mathrm{O}$, pH 5.3. After filtration of the grown cells, the filtrate was concentrated in vacuo and then mixed with one tenth volume of $n$-butanol. The mixture was subjected to the isolation of tremerogen A10 as illustrated in Fig. 1. The biological activity at each purification step was assayed by the method similar to that reported by Reid. ${ }^{4)}$

Tremerogen A-10 was peculiarly adsorbed on some chromatographic materials. When adsorbed on Amberlite XAD-7 column, for example, the active principle could not be eluted with aqueous ethanol and, however, was completely recovered from the eluent with $40 \%$ aqueous ethanol containing $5 \% \mathrm{MgSO}_{4}$. $7 \mathrm{H}_{2} \mathrm{O}$. On Fractogel PGM column, the elution profiles were markedly effected with the composition of elution systems; water, methanol and acetic acid. 


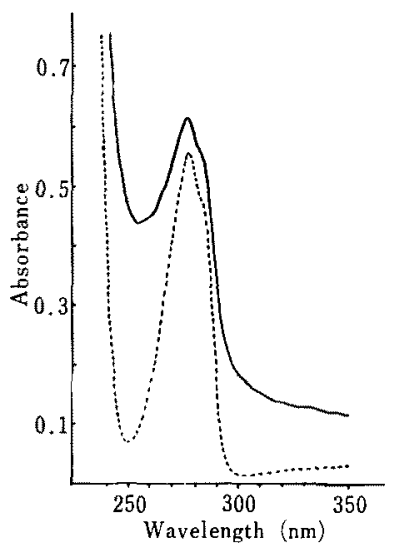

FIG. 2. UV Spectra of Tremerogen A-10 and NAcetyl-L-tyrosine Ethyl Ester.

- tremerogen A-10 in $80 \%$ methanol: acetic acid (99: 1) at a concentration of $1.0 \mathrm{mg} / \mathrm{ml}$.

-----, $\mathrm{N}$-acetyl-L-tyrosine ethyl ester in the same solvent at a concentration of $93 \mu \mathrm{g} / \mathrm{ml}$.

At the final step of purification, the chromatogram monitered by UV absorption at $280 \mathrm{~nm}$ showed a single peak which completely coincided with a peak of biological activity. Further, the isolated sample gave a single spot on each TLC using Silicagel (Merk) and Avicel (Funakoshi) plate with four kinds of solvent systems: 1) $n$-butanol: acetic acid: water (12: 3: 5), Rf 0.36 (Silicagel), 0.57 (Avicel); 2) n-butanol: $n$-propanol: $0.2 \mathrm{M}$ acetic acid (2:1: 3), $R f 0.05$ (Silicagel), 0.46 (Avicel); 3) secbutanol saturated with water $R f 0.16$ (Silicagel), 0.55 (Avicel); 4) n-butanol: pyridine: acetic acid: water (15:10:3:12) $R f 0.69$ (Avicel) In our experiment, tremerogen A-10 was a sole active substance in contrast to the result reported by Reid. ${ }^{4)}$ The isolated hormone, tremerogen $\mathrm{A}-10$, can induce the conjugation tube in $a$ type cell at a concentration of $1 \sim 2$ $\mathrm{ng} / \mathrm{ml}$.

Next we investigated the effects of various chemical reagents and enzymes on tremerogen A-10 in order to get the clue about its chemical properties. When the hormone was incubated with a microbial protease, pronase (Kaken Kagaku), the biological activity became undetectable, suggesting that the substance is a peptide. Then tremerogen $\mathrm{A}-10$ was hydro- lyzed with $5.7 \mathrm{~N}$ hydrochloric acid at $110^{\circ} \mathrm{C}$ for $20 \mathrm{hr}$ and the hydrolyzate was applied onto amino acid analyzer (Hitachi Kla-3B). The molar ratios of detected amino acids were as follows: Asp 2.03, Ser 1.05, Glu 1.03, Pro 1,82, Gly 2.00 , Ala 1.07 , Tyr 0.93 , His 1.05 , Cys 0.74 (estimated from $(\mathrm{Cys})_{2}$ 0.37). As shown in Fig. 2, the UV spectrum of tremerogen A-10 indicated that tryptophanyl residue was not contained in the molecule.

The biological activity of tremerogen A-10 was totally retained after treatment with $\mathrm{N}$ ethylmaleimide, indicating that sulfhydryl function is not involved. This fact was also confirmed by the quantitative analysis of sulfhydryl group using 5,5'-dithio-bis (2-nitrobenzoic acid). Tremerogen A-10 became inactive after treatment with performic acid whereas the absence of disulfide bond was implied by treatment of mercaptoethanol which had no effect on the biological activity of the hormone. Dansylation of the hormone followed by acid hydrolysis gave $\mathrm{N}$-dansyl glutamic acid and suggested that $\mathrm{N}$-terminous of the hormone is Glx. The biological activity of tremerogen A-10 survived after treatment carboxypeptidase A (Miles Lab.), implying that C-terminus might be blocked.

Thus tremerogen A-10 may be a dodecapeptide whose $\mathrm{N}$-terminus is Glx and $\mathrm{C}$-terminus is blocked. The sulf hydryl group in cysteinyl residue is possibly protected in the manner other than disulfide bond formation. The chemical structure of tremerogen A-10 is now under investigation.

Acknowledgement. We wish to express our sincere thanks to Dr. S. Esumi of Kaken Kagaku Co. for his cooperation in a large scale cultivation of $T$. mesenterica. We are also grateful to Drs. A. Sakurai and Y. Kamiya of Institute of Phygical and Chemical Research for amino acid analysis.

\section{REFERENCES}

1) R. M. Whelden, Mycologia, 26, 415 (1934).

2) R. J. Bandoni, Can. J. Bot., 41, 467 (1963).

3) R. J. Bandoni, ibid, , 43, 627 (1965).

4) I. D. Reid, ibid., 52, 521 (1974). 